\title{
Localizing and Lateralizing Value of Epileptic Symptoms in Temporal Lobe Epilepsy
}

\author{
Jean-Marc Saint-Hilaire and Mary Anne Lee
}

\begin{abstract}
The symptoms and signs associated with all stages of a temporal lobe seizure may be helpful in determining both the localization and lateralization of seizure onset. Auras, when present, may be very suggestive of temporal lobe onset and may further localize to a mesiobasal or lateral temporal lobe site of onset. During the ictus, automatisms and motor phenomena may be highly indicative of temporal lobe seizure activity and may even help lateralize the discharge. In the post-ictal period, motor paresis and aphasia are helpful in lateralization. Video E.E.G. data has provided extensive information on the utility of ictal symptomatology in seizure localization. Thus, the seizure semiology provides important adjunctive information in evaluating patients for epilepsy surgery and should be concordant with information obtained from ictal EEG, neuroimaging and neuropsychology.
\end{abstract}

RÉSUMÉ: La valeur des symptômes épileptiques pour la localisation et la latéralisation dans l'épilepsie temporale. Les symptômes et les signes associés à tous les stades d'une crise temporale peuvent aider à déterminer la localisation et la latéralisation du site de déclenchement de la crise. L'aura, quand elle est présente, peut être très suggestive d'un début temporal et peut localiser de façon plus précise le site de déclenchement de la crise. Pendant la crise, les automatismes et les phénomènes moteurs peuvent être hautement indicateurs d'une activité ictale temporale et peuvent même aider à latéraliser la décharge. Dans la période post-ictale, la parésie motrice et l'aphasie peuvent aider à la latéralisation. L'enregistrement vidéo joint à l'ÉEG a fourni beaucoup d'information sur l'utilité de la symptomatologie ictale dans la localisation des crises. Ainsi la séméiologie des crises fournit de l'information complémentaire importante dans l'évaluation de patients épileptiques en vue d'une chirurgie et devrait concorder avec l'information tirée de l'ÉEG ictal, de la neuro-imagerie et de la neuropsychologie.

Can. J. Neurol. Sci. 2000; 27: Suppl. 1 - S1-S5

The study of clinical manifestations of epileptic seizures is considered essential for the localization and the lateralization of the epileptogenic area since the work of J.H. Jackson, ${ }^{1,2,3}$ Penfield and Jasper ${ }^{4}$ added the electroclinical correlation to the anatomico-clinical correlations of Jackson. Their cortical stimulation studies on the awake human brain allowed the determination of the semiology of numerous clinical epileptic manifestations and the functional significance of important cortical areas.

Bancaud and Talairach ${ }^{5}$ stressed the importance of recording spontaneous seizures to determine precisely the origin as well as the diffusion pathways of the epileptic discharge. Precise stereotaxic implantation of intracerebral electrodes (SEG and SEEG) into numerous cortical and sub-cortical structures permitted detailed studies of the localizing value of symptoms or groups of symptoms. Finally, the development of audio-videoEEG recording systems ${ }^{6,7}$ markedly improved the information derived from the study of spontaneous seizures. This methodology is now essential in any centre considering epilepsy surgery. It made us realize that epileptic symptoms previously considered as "localizing" could just as well be originating from different cortical areas.

\section{TEMPORAL LOBE SEIZURE SEMIOLOGY}

Although the general appearance of a seizure is relatively characteristic of its origin, still the first conscious symptom (aura) is the preferred criterion. ${ }^{4,8}$

Depth electrode studies of the diffusion of the epileptic discharge $e^{9,10,11}$ have helped give a better understanding of the complex symptomatology of temporal lobe seizures. Adam et $\mathrm{al}^{9}$ have shown that propagation of the epileptic discharge

From the Centre Hospitalier de l'Université de Montréal, Montréal, Québec, Canada (J-M S-H) and the Department of Clinical Neurosciences, Calgary, Alberta, Canada (MAL).

Reprint requests to: Jean-Marc Saint-Hilaire, Centre Hospitalier de l'Université de Montréal, 1560, rue Sherbrooke est, Montréal, Québec, Canada H2L4M1 
originating in one temporal lobe goes more frequently from the mesio temporal structures to the homolateral mesial frontal areas. From there, probably through the corpus callosum, the discharge spreads to the contralateral mesial frontal and finally to the contralateral temporal lobe. The propagation to the lateral frontal cortex appears later.

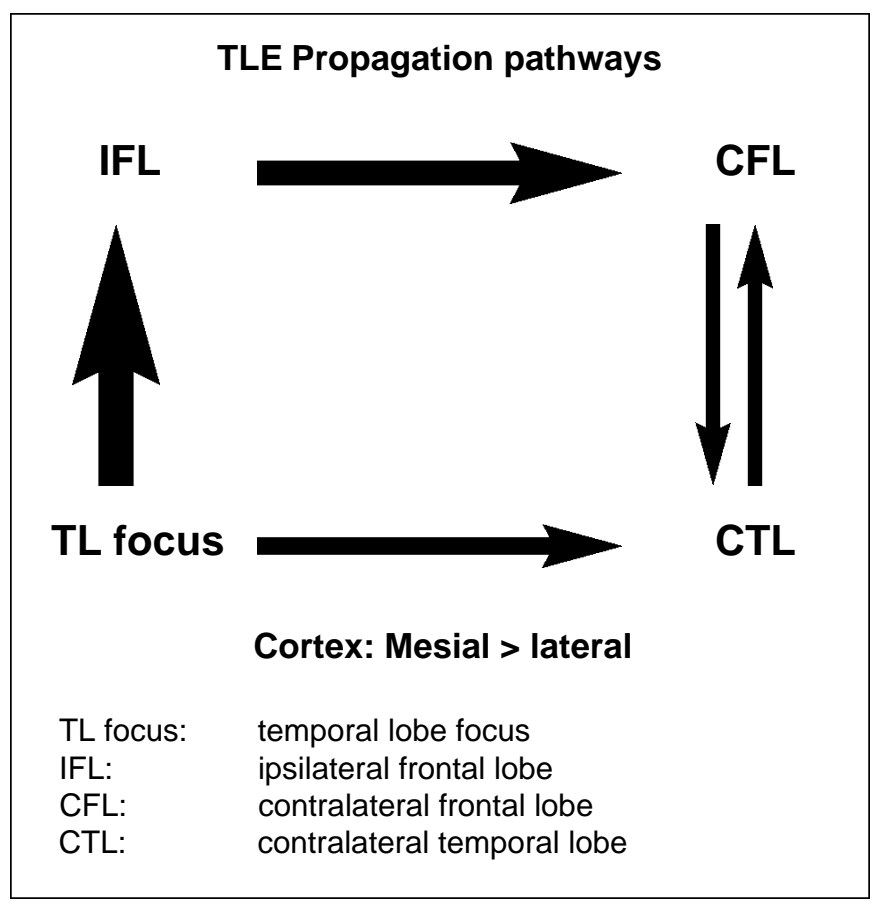

Figure: TLEPropagation pathways

This preferred rapid propagation to the frontal lobes largely explains the complexity and the relative similarity of temporal lobe and frontal lobe symptomatology. There exists also a direct propagation pathway from one temporal lobe to the other without obligatory passing through the frontal pathways. ${ }^{11}$

To complicate matters more, one should realize that the involvement of one anatomical structure by the epileptic discharge may give rise to various symptoms depending on the effect it has on this structure. As Gloor states: "The ictal activity involving an anatomical substrate can produce ictal behavior changes in one of two ways: either it can activate the function that is represented there, or it can, on account of its unphysiological nature, interfere with it. "12 So, besides the effects of propagation to numerous structures, one should consider the negative or the positive impact of the discharge on these structures, to explain the wide variety of behavioral manifestations.

The negative impact can have its effect on the structure which itself is involved in the epileptic discharge. This negative impact can also create its effect at a distance, on structures not actually involved in the discharge by the fact that these structures are no longer controlled by the structure which was affected directly by the discharge (indirect negative effect).

An example can illustrate these different mechanisms. A female patient, 27-years old, was investigated for simple and complex partial seizures of left temporal origin. She remained fully conscious during the whole seizure described below. First, she had an epigastric sensation (positive effect) then she felt a "déjà-vu" with the impression that she could predict what would happen after (positive). This was followed by nausea (positive), and at the same time she was unable to speak although she could obey some simple commands (negative direct). One also noticed oro-alimentary automatisms with lip smacking and swallowing. She remained aphasic for five minutes after the seizure. When questioned, she said she remembered everything, including the commands which had been given to her but that she was unable to answer. Asked why she presented chewing and deglutition, she said that it was in reaction to the nausea. Although automatisms in general arise from a negative indirect effect of the discharge, they can be more conscious than they appear, as in this case, and would then be a positive effect of the discharge.

The symptoms of temporal lobe seizures can be separated into those arising from ictal discharges in the mesio-basal temporal lobe and those arising from the lateral neocortical temporal lobe. ${ }^{13}$

\section{Mesio-basal auras}

Auras of seizures arising from the mesio-basal temporal lobe typically consist of visceral, cephalic, gustatory, dysmnestic or affective symptoms. A rising epigastric or chest sensation is the commonest aura and has been reproduced by stimulation of the amygdala in awake patients during surgery or in patients with implanted electrodes. Other viscerosensory symptoms produced by amygdaloid stimulation consist of nausea, palpitations, a feeling of warmth or cold and shivering. Although the amygdala is not the only site to produce these symptoms it is the commonest site. Auras may also consist of numerous autonomic and respiratory changes and these have also been reproduced (although not exclusively) by amygdaloid stimulation. Symptoms and signs include mydriasis, flushing or pallor (usually of the face), lacrimation, tachycardia palpitations, apnea, salivation, borborygmi, flatulence, piloerection, sweating and the urge to void or defecate with occasional involuntary urination or defecation. These symptoms may occur in isolation or often in combination with affective symptoms such as fear.

A number of symptoms referred to as experiential phenomena occur as auras in patients with temporal lobe seizures and Gloor $^{13}$ has subdivided these into affective, perceptual, and mnemonic phenomena.

Fear is the commonest affective symptom occurring in up to $50 \%$ of temporal lobe seizures and again has been reproduced by stimulation of the amygdala and less commonly in association with viscerosensory and autonomic symptoms. It may be associated with fearful hallucinations or memory flash backs. Fear is not always reported but is implied by changes in facial expression or behaviour. The lack of subjective recording may be explained by anterograde amnesia occurring during the seizure.

There are a number of negative emotions other than fear that can be produced by discharges arising in the amygdala and these consist of anger, disgust, guilt, depression, sadness and loneliness. Directed aggressive behaviour associated with these negative emotions, however, rarely occurs. ${ }^{14}$

Positive emotions as opposed to negative ones, occur much less commonly. These may consist of happiness, exhilaration, 
mirth with laughter and erotic excitement. Erotic excitement associated with libidinous feelings has been reported almost exclusively in women and may be associated with an increase in vaginal secretions and even orgasm. Thirst and the urge to drink (or, rarely, eat) are occasional affective symptoms associated with temporal lobe seizures.

Various perceptual phenomena may occur in temporal lobe epilepsy and visual and auditory events are the most common. These are subdivided into illusions and hallucinations. Illusions are distortions or alterations in perception of actual events such as changes in sound intensity or visual distortions. These most commonly arise from discharges in the auditory or visual association cortex. Visual and auditory hallucinations are de novo creations but are often associated with a personal memory. The hearing of a familiar voice is a common auditory hallucination but rarely does the patient recall what was said.

Olfactory and gustatory hallucinations may be reproduced by amygdaloid stimulation but are more likely to arise from the centro-parietal operculum and adjacent insula or the posterior orbital frontal cortex.

"Déjà-vu", which is an illusion of memory, and memory flash-backs, which are the reactivation of past memories are the two forms of mnemonic phenomena which can be activated by temporal lobe seizures or stimulation. These are most easily elicited by stimulation of the amygdala but may also be elicited by stimulation of the lateral temporal neocortex.

\section{Lateral temporal lobe epilepsy}

Visual and auditory hallucinations occur more commonly from discharges arising from the lateral temporal lobe than from the mesio-basal temporal lobe although there is considerable overlap in clinical symptomatology. The hallucinations may be crude or elaborate and commonly there are illusions of size (micropsia, macropsia), shape, weight, distance or sound. Affective, psychic or visceral auras may occur but are less common than in mesio-basal temporal lobe seizures. Consciousness may be preserved for longer than in mesiotemporal lobe seizures.

\section{Automatisms}

The term automatism refers to motor behaviours occurring during complex partial seizures. These may be simple or exceedingly complex and usually bear no relationship to events occurring in the patient's environment. Automatisms do not occur at the beginning of the seizure but often extend into the post-ictal phase.

The simplest and most common form of automatism is referred to as oro-alimentary automatism and consists of rhythmic chewing, swallowing or lip-smacking. Electrical stimulation of the amygdala or surrounding structures does not produce these rhythmic movements unless a seizure or afterdischarge is produced. The amygdala does project to neurons in the lower brain stem which are involved in the integration of the masticatory motor program. It is not known whether these projections exert an excitatory or inhibitory influence. Gloor ${ }^{12}$ tends to favour the theory that the state of automatism is a negative phenomenon reflecting paralysis of temporal lobe function. The fact that a number of automatisms continue into the post-ictal state further supports the hypothesis that the state of automatism is one of paralysis of function of the temporal lobe and additional cortical and sub-cortical structures to which the seizure discharges spread. But, as in the case presented previously, oro-alimentary automatisms can be conscious and could be a reaction to an ictal autonomic symptom.

The presence of anterograde amnesia during complex partial seizures reflects ictal interference with normal function of the hippocampal system.

Other relatively common simple automatisms consist of selfinspection and self-manipulation such as plucking at clothing or objects or repetitive motor activity. More complex automatisms

\section{Table: Characteristics of "pure" frontal and "pure" temporal lobe seizures}

\section{Electronic permission not granted}

Saint-Hilaire, J.M. Les crises et leur sémiologie. In: Rougier, A., SaintHilaire, J.M., Bouvier, G. et Loiseau, P. (Eds.) Investigation et traitement chirurgical de l'épilepsie. Paris: Masson. Neurochirurgie 1992;38 (Suppl. 1) 34-43. Reprinted with permission. 
occur as well, such as walking, running, undressing and even going to the bathroom and voiding. Vocalization is also common and, if there are identifiable words, this suggests a non-dominant seizure focus.

\section{Motor phenomena}

Excluding the secondary generalized seizures, motor manifestations are either tonic or clonic and can be found in temporal lobe seizures. A frequent type of seizure is the association of dystonic posturing contralaterally and simple automatism of a limb ipsilaterally to the focus. ${ }^{15}$ It suggests a mesio-temporal origin of the seizure.

Ipsi or contralateral head and eye deviation is frequent in temporal lobe epilepsy, ${ }^{16,17}$ and usually corresponds to the spread of the discharge to the frontal lobe ${ }^{18}$ as it is not seen in seizures remaining in the temporal lobe (Table). Hand and eye deviation occurs later than 18 seconds in temporal lobe seizures as compared to earlier than 18 seconds in extra-temporal seizures (mainly frontal). Hand and eye deviation occurring just before a secondarily generalized seizure has more lateralizing value, that is contralateral to the epileptogenic area. ${ }^{19}$

\section{Post-ICTAL SYMPTOMS}

It has long been accepted that post-ictal paresis is a good lateralizing sign in epilepsy. ${ }^{20}$

Post-ictal aphasia has an excellent lateralizing value in temporal lobe epilepsy. ${ }^{21,22}$ When present, its specificity is $100 \%$ in epilepsy of the dominant temporal lobe. However, the absence of post-ictal aphasia does not exclude that the epileptic focus is in the dominant temporal lobe. It has been shown by depth electrode studies that the epileptic discharge must involve the temporal and/or frontal speech areas to produce post-ictal aphasia. ${ }^{22}$ Thus the importance of repeated testing of post-ictal language in more than one seizure.

\section{TEMPORALVS EXTRA-TEMPORAL EPILEPSIES}

Occipital epilepsy is diagnosed with difficulty only on a clinical basis. If visual symptoms are not reported at the beginning of the seizure, ${ }^{23}$ the ensuing symptoms may suggest a temporal or even a centro-parietal origin. The same is true for parietal epilepsy, unless early motor or sensory symptoms are reported. ${ }^{24}$ Practically, the problem is to decide between a temporal and a frontal origin.

In the frontal lobe, it is almost hopeless to relate a symptom or a group of symptoms to a precise area. There is a large overlap of the various manifestations. ${ }^{25}$ The distinction between frontal lobe and temporal lobe epilepsies is the main problem in the investigation for epilepsy surgery. Two systematic studies of this subject ${ }^{25,26}$ agree on the difficulty of giving a localizing value to one symptom or to a group of symptoms. On the basis of spontaneous seizures recorded with depth electrodes in the frontal and temporal lobes, ${ }^{18}$ we could compare "pure" temporal to "pure" frontal lobe seizures, that is without diffusion outside the lobe of origin (Table). We expected to isolate the more specific symptoms of each lobe. In summary, very few symptoms were specific for each lobe. Hallucinations, visceromotor phenomena and oro-alimentary automatisms were strongly related to a temporal origin. Motor manifestations other than clonic, (head and eye deviation, tonic contraction of one limb) were directing to a frontal origin. However, this "pure" type of seizure is relatively rare in frontal lobe epilepsies. Another study based on the location of the lesion ${ }^{26}$ gives similar conclusions. It illustrates the close connections between frontaltemporal regions ( $c f$. Figure) and it stresses the importance of the first symptom as a clue to localization.

\section{ConClusion}

In spite of a meticulous analysis made easier by audio-video EEG recordings, the localization and even more the lateralization of a large proportion of temporal lobe epileptic seizures is not as good as expected. Few symptoms are clearly lateralizing. This is in accord with the known fact that the epileptic discharge tends to diffuse at a distance and rarely remains localized in the structure of origin. More frequently one observes a "borrowed" symptomatology derived from the secondary invasion of distant structures. This stresses the importance of the first symptom.

The main problem is to distinguish between frontal and a temporal lobe epilepsy. Automatisms, although considered the most characteristic manifestation of temporal lobe epilepsies, can originate from extra-temporal structures as well. Hallucinations and psychic phenomena, found almost exclusively in temporal lobe epilepsies, are, unfortunately, very rare.

Generally, careful analysis of clinical manifestations allows hypothesis as to the localization and lateralization of the epileptogenic zone. Most of the time, however, this hypothesis will be approximate and will need the support of other tests, invasive or otherwise.

\section{REFERENCES}

1. Jackson JH. A study of convulsions. Transactions of the St.Andrews Medical Graduates Association 1870; 3: 1-45. Republished in : Selected writings of Jackson JH, Taylor J. Eds. London: Hodder and Stoughton, $1931: 8-36$.

2. Gastaut $\mathrm{H}$ and Broughton R. Epileptic Seizures: Clinical and Electrographic Features, Diagnosis, and Treatment. Charles C. Thomas, Publisher, Springfield, Illinois, 1972.

3. Mikati MA and Holmes GI. Temporal Lobe Epilepsy. The Treatment of Epilepsy: Principles and Practices. Wyllie (Editor) Lea and Febiger, 1993.

4. Penfield W, Jasper H. Epilepsy and the Functional Anatomy of the Human Brain. Boston: Little, Brown and Company, 1954: 896 pages.

5. Bancaud J, Talairach J, Bonis A et al. La stéréo-électroencéphalographie dans l'épilepsie. Informations neurophysiopathologiques apportées par l'investigation fonctionnelle stéréotaxique. Paris: Masson, 1965: 321 pages.

6. Saint-Hilaire JM, Bouvier G, Lymburner J, Picard R, Mercier M. La stéréo-électroencéphalographie synchronisée avec l'enregistrement visuel et sonore dans l'exploration chronique de l'épilepsie. L'Union médicale du Canada 1976; 105: 1538-1542.

7. Penry JK, Porter RJ, Dreifus FE. Simultaneous recording of absence seizures with videotape and electroencephalography. A study of 374 seizures in 48 patients. Brain 1975; 98: 427-440.

8. Wieser HG. Electroclinical Features of the Psychomotor Seizure. New York: Gustav-Fisher, Stuttgart 1983: 242 pages.

9. Adam C, Saint-Hilaire JM and Richer F. Temporal and spatial characteristics of intracerebral seizure propagation: prediction value in surgery for temporal lobe epilepsy. Epilepsia 1994; 32: 1065-1072.

10. Lieb JP, Dasheiff RM, Engel J Jr. Role of the frontal lobes in the propagation of mesial temporal lobe seizures. Epilepsia 1991; 32: 
822-832.

11. Spencer SS, Williamson PD, Spencer DD et al. Human hippocampal seizure spread studied by depth and subdural recording: the hippocampal commissure. Epilepsia 1987; 28: 479-489.

12. Gloor P. Neurobiological substrates of ictal behavioral changes. In: Smith D, Treiman D and Trimble $M$, eds. Advances in Neurology; 55. New York: Raven Press, 1991: 1-34.

13. Gloor P. The Temporal Lobe and Limbic System. Oxford University Press, 1997: 695-708.

14. Saint-Hilaire JM, Gilbert M, Bouvier G, Barbeau A. Epilepsy and aggression: two cases with depth electrodes studies. In: Epilepsy Up-dated: Causes and Treatment. Chicago: Preston Robb, 1980: 145-176.

15. Dupont S, Semah F, Boon P, et al. Association of ipsilateral motor automatisms and contralateral dystonic posturing; a clinical feature differentiating medial from neocortical temporal lobe epilepsy. Arch Neurol 1999; 56: 927-933.

16. Robillard A, Saint-Hilaire JM, Mercier M and Bouvier G. The lateralizing and localizing value of adversion in epileptic seizures. Neurology 1983; 33: 1241-1242.

17. Ochs R, Gloor P, Quesney LF, Ives J, Olivier A. Does head turning during a seizure have lateralizing or localizing significance? Neurology 1984; 34: 884-890.

18. Saint-Hilaire JM. Investigations pré-chirurgicales. Neurochirurgie 1992; 38 (Suppl. 1): 34-66.
19. Chee ML, Kotagal P, Van Ness PC, et al. Lateralizing value in intractable partial epilepsy: blinded-multiple-observer analysis. Neurology 1993; 43: 2519-2525.

20. Jackson JH. On temporary paralysis after epileptiform and epileptic seizures: a contribution to the study of dissolution of the nervous system. Brain 1881; 3: 433-551.

21. Privitera MD, Moris GL, Gilliam F. Postictal language assessment and lateralisation of complex partial seizures. Ann Neurol 1991; 30: 391-396.

22. Adam CR, Adam C, Rouleau I, Saint-Hilaire JM. Postictal aphasia and paresis: lateralizing value and neurophysiological correlates in partial seizures. Epilepsia 1993; 34: 131-132.

23. Williamson PD, Spencer SS. Extratemporal complex partial seizures. Epilepsia 1986; 27 (Suppl. 2): 46-63.

24. Ajmone Marsan C, Goldhammer L. Clinical ictal patterns and electrographic data in cases of partial seizures of fronto-centralparietal origin. In: Brazier MAB eds. Epilepsy. Its Phenomena in Man. New York, London: Academic Press, 1973: 235-258.

25. Veilleux F, Saint-Hilaire JM, Giard N, Turmel A, Bernier GP et al. Clinical manifestations of seizures of the human medial frontal lobe. In: Chauvel Pet al. eds. Advances in Neurology, New York: Raven Press, 1992: 57: 245-255.

26. Manford M, Fish DR and Sharvon SD. An analysis of clinical seizure patterns and their localizing value in frontal and temporal lobe epilepsies. Brain 1996; 119: 17-40. 